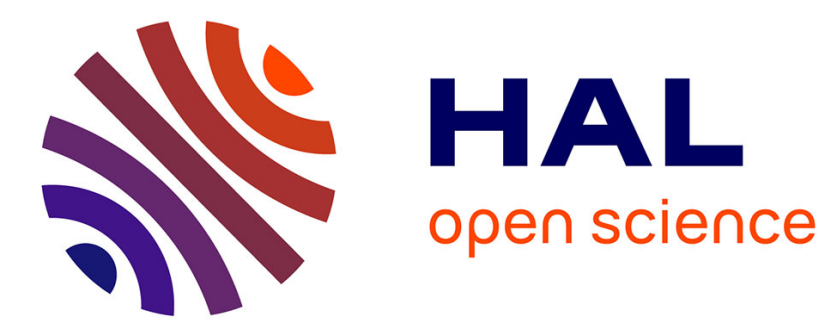

\title{
Organizational Learning: A Process Between Equilibrium and Evolution
}

David Cayla

\section{To cite this version:}

David Cayla. Organizational Learning: A Process Between Equilibrium and Evolution. Journal of Economic Issues, 2008, 42 (2), pp.553-560. halshs-00267975

\section{HAL Id: halshs-00267975 https://shs.hal.science/halshs-00267975}

Submitted on 29 Mar 2008

HAL is a multi-disciplinary open access archive for the deposit and dissemination of scientific research documents, whether they are published or not. The documents may come from teaching and research institutions in France or abroad, or from public or private research centers.
L'archive ouverte pluridisciplinaire HAL, est destinée au dépôt et à la diffusion de documents scientifiques de niveau recherche, publiés ou non, émanant des établissements d'enseignement et de recherche français ou étrangers, des laboratoires publics ou privés. 


\title{
Organizational Leaming: A Process Between Equilibrium and Evolution'1
}

David Cayla

\begin{abstract}
This paper aims to analyze learning as a two-type process. A dynamic equilibrium process represents a stable learning process, that may express an individualistic behavioral learning or an organizational adaptation. A teleological process represents an intentional, goal-oriented, learning process. This second type of learning can express an individualistic cognitive learning or a managerial organizational change. It is argued that this learning typology can helps to understand why similar organizations or individuals may learn differently when confronted to the same environmental stimuli.
\end{abstract}

Keywords: Dynamic Equilibrium, Learning, Organizational Learning, Teleology.

JEL Classification Codes: B52, D83, L20, M10

Ulrich Witt (2005) recently emphasized that economic theories still have difficulties in understanding "why" and "how" organizations change. On the one hand Neoclassical approaches and New Institutional Economics based on the equilibrium notion, tend to focus on what organizations should do, but ignore the question of how they reach it. On the other hand, evolutionary economists tend to forget the intentional dimensions of change by focusing on fitness and adaptation. With the first perspective, change is considered as a goal without process; with the second, it is an infinite process that barely has a goal.

Evidence captured by empirical analysis may change this perspective. As Marta Feldman (2000; 2003) or Bénédicte Reynaud (2005) present it, routines are not performed by blind agents, but "by people who think and feel and care" (Feldman 2000, 614). Even if we accept Nelson and Winter's (1982) analogy, and if we compare routines with genes, it seems necessary to integrate

\footnotetext{
${ }^{1}$ The author is a researcher fellow at the University Pantheon-Sorbonne and INSEEC Business School. He is very grateful to Dr Tao (Sherry) Kong for her helpful comments. This paper was presented at the annual meeting of the Association for Evolutionary Economics in New Orleans, LA, January 4-6, 2008.
} 
the fact that unlike biological processes, economic mutations do not appear randomly (Metcalfe 2005). ${ }^{2}$ Obviously, they are often the product of a conscious intention. As Witt (2005) explains, changes in an organization are not only conducted by a mere adaptation to external conditions, but also rest on strong internal considerations where hierarchical decisions have an important role to play. This perspective may help to analyze the cognitive and intentional dimensions of change in organizations.

It is interesting to note that more than a century ago, Thorstein Veblen (1898) was aware of the importance of human intentions in evolution, emphasizing the "teleological" aspects of economic actions. For Veblen, "the change is always in the last resort a change in habits of thought" $(1898,391)$. Following this perspective, it seems necessary to restore the teleological aspects of human behavior in modern evolutionary analysis. In other words, to escape from a strict Darwinian analogy and to analyze human changes as goal-oriented processes.

The aim of this paper is to contribute to the above mentioned perspective by characterizing two different types of change processes that have features of both "equilibrium" and "evolution.". In doing so, we will follow Pierre Garrouste (2007), who considers that these two economic conceptions may be more complementary than they are substitutable. The first two sections study the dynamic equilibrium process and the teleological processes, respectively. The third section discusses the implication of this typology to the study of organizational learning, and concluding remarks are provided in the final section.

\section{Leaming and the Dynamic Equilibrium Process}

Learning can be defined as a process of permanent changes in behavior that result from environmental interactions (Lazaric, Monnier and Paulré 1995; Garrouste 1999). Two kinds of learning are compatible with this definition. Behavioral learning is a learning process that does not modify the main features of the cognitive system. Learning to bike is an example of behavioral learning. Even if it implies a small cognitive dimension, it does not change the biker's main intellectual conceptions (its representations system). In contrast, cognitive learning is a learning process that modifies the agent representations and interacts with its specific visions or preferences.

\footnotetext{
${ }^{2}$ Metcalfe (2005) believes that intention does not have to be removed for evolutionary theory because it strengthens the evolutionary logic by increasing the variety and the fitness of mutations.
} 
Learning appears as a typical intermediate concept that can fill the gap between the equilibrium and evolutionary approaches. On one hand, it needs the evolutionary approach to clarify its process in terms of path dependency or irrevocability (Georgescu-Roegen 1971); on the other hand it at least needs the equilibrium logic to understand its final perspective, its rules or its goal. This feature is important in terms of distinguishing a learning process from a random change. Learning is an organized change. For this reason it is a process that follows rules, and that needs pedagogy. The final results of a learning process may be infinite, but they are not without limit. If I am engaged in bike learning, I will not become a better econometric analyst.

Garrouste (2007) stresses that it can be interesting to develop economic models based on both the equilibrium and evolutionary notions. To support his assertion, he develops the concept of dynamic equilibrium. For Garrouste, a dynamic equilibrium characterizes a system on which "the whole forces that applies on it do not make it go away from a specific course" (Garrouste 2007, 441). In other words, it is a stable process of evolution.

A system that is in dynamic equilibrium can tend toward a state or a set of states (if its end is given), or it may only follow a trajectory or a logic, if it does not have a given end. A dynamic equilibrium process is therefore compatible with the notion of intention. As Garrouste (2007, 446) explains, the final characteristics of this kind of process depends on the type of rules it follows, which may be ex ante determined. Because the rules that direct a dynamic equilibrium process do not change, the evolution of the behavior of the learning system is limited inside a certain path.

A dynamic equilibrium may express a move in a known environment. First, the agent decides her move, taking into account what she knows about the space. Once the move is determined, she will engage herself in the moving process. Some foreseeable perturbations (if the space is known) may occur that will bring her to adapt her move without changing the rules of her moving process. Therefore, the changes of the agent behavior are stable, and her decisions will stay in an ex ante determined trajectory. Her rationality is then bounded inside this trajectory.

\section{The Teleological Processes}

In an uncertain and changing environment, it may be necessary to consider the possibility for the rules to change during the evolution process. This new kind of process refers to Veblen's 
teleological principles, i.e. the integration of the agent's intentions in the characteristics of the process. A teleological process can be defined as a dynamic equilibrium whose rules are determined endogenously, as a relation between the system's behavior and its intentions. In contrast to the dynamic equilibrium, the rules and the trajectory of a teleological process may change. This change may be due to a change in the system's intention or the system's evaluation of the relation between its intention and its behavior.

Charles Taylor (1964) defines a teleological behavior as a goal oriented behavior that is opposed to a mere stimulus-response behavior. Following Taylor, Norman Malcolm $(1967,98)$ defines the logic of a teleological behavior as:

Whenever the state of $\mathrm{S}$ and of environment $\mathrm{E}$ is such that $\mathrm{B}$ is required for some event $\mathrm{G}$, then B occurs.

With $B$ representing the system $S$ behavior, $E$ the environment and $G$ the goal of $S$. It is possible to transform this expression into the following formula:

(1) $(\mathrm{s})\left\{\left(\mathrm{B}_{\text {(I) }} \rightarrow \underset{\text { (If }}{\mathrm{G}}\right) \rightarrow \mathrm{B}_{\mathrm{s}}\right\}$

The arrows represent the logical links between two events. For example, a stimulus-response behavior can be simply expressed by:

(2) $(\mathrm{s}) \mathrm{E} \rightarrow \mathrm{B}_{\mathrm{s}}$.

Expression (1) is interesting because it implies two logical links. Link I expresses the relation between behavior B and goal G, whereas link II represents the relation between the first link and the effective behavior of S.

This expression is useful to distinguish the two necessary conditions of a teleological behavior. The agent must first accomplish action B (link II), and second, must have the intention to do so by evaluating the relation between B and G (link I). Taken separately, however, these two conditions are not sufficient. As Taylor says: "I may decide to stab someone, and, before I can execute my intention, my arm may be pushed" $(1964,33)$. It is therefore the whole expression that has to be taken into account in a teleological behavior, and not only the coincidence of both the intention and the behavior.

In expression (1), Link II represents the effective behavior of S, whereas link I only describes a perception. As Taylor explains, with an intentional system it is not necessary that action B produces G effectively for the occurrence of B. "What is sufficient (in the absence of interfering 
factors) is that the "system" believes that B is required for $G$, or sees B as required for G" (Taylor 1964 , 62). It is therefore impossible to reduce (1) to a relation of the kind $G \rightarrow B$. To say it differently, agents can be wrong. The behavior of S may not reach her goal if her beliefs do not reflect the reality of E. More than twenty years earlier than Taylor (1964), this fact had been underlined by Albert Hofstadter (1941, 33) who explained that in a teleological behavior, knowing the goal is generally not sufficient to correctly foresee the behavior. For Hofstadter, a teleological behavior rests on two different dimensions. First, the "objective dimension" reflects the effective behavior of $\mathrm{S}$ that is given by link II, which can be observed by any element of $\mathrm{E}$. Second, the "subjective dimension" reflects the system's beliefs that result from its cognitive system (link I). Unlike the former, the subjective dimension of a teleological behavior cannot be observed directly from outside, but can be deduced from the objective behavior (Hofstadter 1941, 34).

The changing process of a teleological behavior is what we define as a teleological process. The main features of a teleological process are analogous to the ones of a teleological behavior. Like a teleological behavior, a teleological process is based on a double dimension, which represents a double equilibrium. The first equilibrium expresses, like in a dynamic equilibrium, the stability of the rules that guide a behavioral process. The second equilibrium expresses the stability of representations and perceptions (i.e., the cognitive system) that determines the behavioral process. As long as the cognitive system is unchanged, the rules that direct the evolution of the behavior stay in equilibrium. The process followed by the system will be similar to a classic dynamic equilibrium process. However, during the learning process, some changes may appear in the agent's cognitive system. These changes will be expressed by a change in the agent's objectives, or a change in her perception of the relation between her behavior and her goals (a change in $B \rightarrow G$ ). In this case, the rules of the process will have to change in order to be aligned with the new cognitive system.

A teleological process may express a move in an unknown environment. After the agent has decided a general route for her move, she will take the opportunity to revise her path during her progress, taking into account the information and knowledge she has gathered from her real environment.

The logic of a teleological process differs from the dynamic equilibrium in three aspects. First, it rests on an "unbounded" rationality principle. In a teleological process, the agent not only 
questions the means, but also the finalities of the process. Secondly, it rests on a strong subjective dimension. The features of the process depend not only on the environment and the preferences of the agent, but also the specific characteristics of her cognitive system. Two persons with the same objectives, in the same environment, and with the same cognitive limitations may act differently if their perceptions are different and if they do not interpret identically the $\mathrm{B} \rightarrow \mathrm{G}$ relation. Finally, a teleological process is more open, in its final results, than a dynamic equilibrium. It involves a strong uncertain dimension, partly due to the uncertainty of the environment, but more fundamentally, due to the uncertainty of the knowledge creation process.

\section{Types of Process and Types of Organizational Leaming}

We are now able to distinguish two types of learning processes:

1. A dynamic equilibrium process represents a stable changing process, directed by stable rules. It follows a stable (and therefore mainly foreseeable) trajectory. The actions of an agent who follows a dynamic equilibrium are limited and her rationality can be considered as bounded.

2. A teleological process is a process in which the finality and the rules can be revised in relation to an end. It rests on two equilibrium levels instead of one. Unlike the dynamic equilibrium process, its finality is uncertain and it necessitates a more complete rationality model that can integrate the agent's subjective dimension.

At an individual level, these two types of processes may express two types of learning. As it is discussed in the first section, behavioral learning is a learning that does not affect the agent's cognitive system. For this reason, behavioral learning may be analyzed as a teleological process where the cognitive dimension will stay unchanged, that is, as a dynamic equilibrium process. On the other hand, cognitive learning is a kind of learning that affects an agent's representations. As a consequence, this kind of learning has to be analyzed as a full teleological process with an uncertain end and trajectory.

At an organizational level, learning can be defined as a process of change in organizational behavior. Two types of organizational learning can therefore be defined. First, an organizational learning can be defined as an adaptive process that occurs in response to a change in the 
environment. This type of learning appears while the main goals of the organization stay unchanged. It is analogous to an individual behavioral learning, or, more specifically, to a Darwinian evolutionary process. This type of learning can also refer to an internal coordination process. It therefore implies a collective and reciprocal adaptation of individual behaviors that end toward a Hayekian equilibrium. Second, an organizational learning can refer to a guided organizational change. This type of change is not due to a change in the environment but to a conscientious managerial decision. It rests on a specific strategy that is related to a specific goal, or on a more implicit collective intention.

In our typology, organizational adaptation/coordination refers to a dynamic equilibrium process. It follows a stable set of rules, which means that its end can mostly be foreseen. Guided organizational changes, however, need to be analyzed as a teleological process. The results and consequences of this type of organizational learning may therefore be difficult to predict because the trajectory of such a process is founded on a cognitive system which has specific goals and intentions. However, as Hofstadter showed, it is possible to deduce the goal that the system aims to reach by studying the effective organizational behavior over time.

\section{Conclusions}

The distinction between teleological learning processes and dynamic equilibrium learning processes (in other words, between adaptive processes and guided processes), may help us understand the reason why two communities may act differently in the face of the same disturbance in their environment. For example, Reynaud (2005) empirically studied the way a team adapts its collective behavior when it is confronted by new rules that come from the management. Her implicit hypothesis is that the way the team will adapt to these rules will not depend on the way it is internally structured, but on the nature of the routines it will implement in order to follow the rules. The above analysis leads us to a different conclusion: If the team that is confronted by new managerial rules is centrally controlled by an authority (i.e., a leader) that aims to follow a specific intention, the reaction of the team to these new rules will not be the same as that of a team structured as a self-organized system. In the first case, it will develop a teleological changing process that is hard to foresee and that may contradict the first management's anticipations; in the second case, the team will only adapt itself to the new rules in an inter-individual and decentralized process, in a dynamic equilibrium process. 
In terms of a future research agenda, more empirical research is needed to examine the distinction between adaptive and guided change processes. Moreover, it may be particularly interesting to evaluate the role of collective intentions in the way organizations adapt themselves to a change in their environment.

\section{References}

Feldman, Martha, S. "Organizational Routines as a Source of Continuous Change." Organization Science 11, 6 (2000): 611-629.

- "A Performative Perspective on Stability and Change in Organization Routines." Industrial and Corporate Change 12, 4 (2003): 727-752.

Garrouste, Pierre (1999), “Apprentissage, Interactions et Création de Connaissance.” Revue d'Économie Industrielle 88 (1999) : 137-151.

—. "Équilibre et evolution en économie." In Leçons de philosophie économique, vol. 3, edited by Alain Leroux and Pierre Livet, pp. 439-458. Paris: Economica, 2007.

Georgescu-Roegen, Nicholas. The Entropy Law and the Economic Process. Cambridge, MA: Harvard University Press, 1971.

Hofstadter, Albert. "Objective Teleology.” The Journal of Philosophy 38, 2 (1941): 29-39.

Lazaric, Nathalie, Jean-Michel Monnier and Bernard Paulré (1995), “Introduction Générale.” In Coordination économique et apprentissage des firmes, edited by Nathalie Lazaric and Jean-Michel Monnier, pp. vii-xx. Paris: Economica, 1995.

Malcolm, Norman. "Explaining Behavior.” The Philosophical Review 76, 1 (1967): 97-104.

Metcalfe, J. Stanley. "Evolutionary concepts in relation to evolutionary economics." In The Evolutionary Foundation of Economics, edited by Kurt Dopfer, pp. 391-430. Cambridge, MA: Cambridge University Press, 2005.

Nelson, Richard R. and Sidney G. Winter. An Evolutionary Theory of Economic Change. Cambridge, MA: Press of Harvard University Press, 1982.

Reynaud, Bénédicte. "The Void at the Heart of Rules: Routines in the Context of RuleFollowing Observations from a Workshop of the Paris Metro." Industrial and Corporate Change 14 (2005): 847-871.

Taylor, Charles. The Explanation of Behaviour. London: Routledge, 1964.

Veblen, Thorstein. "Why is Economics not an Evolutionary Science?" The Quarterly Journal of Economics 12, 4 (1898): 373-397.

Witt, Ulrich. "The Evolutionary Perspective on Organizational Change and the Theory of the Firm." In The Evolutionary Foundations of Economics, edited by Kurt Dopfer, pp. 339-364. Cambridge: Cambridge University Press, 2005. 